\title{
Determination of Changes in the Brain in Bipolar Disorder by Im- aging Methods and its Reflections in Nursing Care
}

\author{
Özlem KAŞTAN ${ }^{1 *}$ and Gülşah ACAR ${ }^{2}$ \\ ${ }^{1}$ Assistant Professor, Akdeniz University, Antalya, Turkey \\ ${ }^{2}$ Research Assistant, Akdeniz University, Antalya, Turkey
}

*Corresponding author: Özlem KAŞTAN, Assistant Professor, Akdeniz University, Antalya, Turkey, Tel: +90505-2598348,

E-mail: ozlemzumre@akdeniz.edu.tr

\begin{abstract}
Bipolar disorder is a chronic brain disease characterized by lifelong repetition and remissions and emotional state fluctuations that vary from deep depression to extreme happiness. Although there are many studies on the neurobiological basis of bipolar disorder, its pathophysiology is not fully known. Brain imaging methods are potentially very important for obtaining information about the pathophysiology of bipolar disorder. Recent advances in brain imaging methods have increased the knowledge about abnormalities in neural systems underlying the disease and in various regions of the brain. Even though there is no more suspicion that bipolar disorder is a brain disorder, the underlying neuroanatomical causes remain uncertain. Studies indicate that all brain regions are structurally and functionally affected in bipolar patients. It has been investigated that there are structural and functional changes in many regions of the brain in bipolar disorder. It's important to know these changes in the brain in bipolar disorder for a good nursing care.
\end{abstract}

\section{Keywords}

Neuroimaging, Bipolar disorder, Nursing care

Bipolar disorder is a disease characterized by lifelong repetition and remissions and emotional state fluctuations that vary from deep depression to extreme happiness. Furthermore, it is a chronic brain disease in which an individual can return to a completely healthy emotional state [1]. Bipolar disorder is characterized by emotional periods classified as depressive, manic/hypomanic, or mixed periods. The mania/hypomania or mixed periods that need to be seen in order for the diagnosis of bipolar disorder to be established are those that define elevated mood over the usual mood line of the person. The core pathology of bipolar disorder is elevated mood [2]. There is an exaggerated increase in self-esteem, size considerations, a decrease in the need for sleep, more talkative than ever, flies of thought, distracting attention are seen in the manic period off the illness. Depressed mood, loss of interest and pleasure, decreased or increased desire to eat, insomnia or excessive sleep, worthlessness, etc. symptoms are seen in the depressive period of the illness.

Bipolar disorder is a serious psychological, economic, and social burden in patients, families, and society. For this reason, it is very important to uncover the neurobiological mechanisms underlying this disorder [3]. Research into neurobiology of bipolar disorder aims to elucidate the processes that lead to the disease and to develop therapies for these processes. These investigations are also seeking to identify biological markers that will contribute to the diagnostic accuracy of the disease, provide treatment plans based on evidence, enable early diagnosis and assess treatment response. The International Society for Bipolar Disorders Biological Markers Working Group recommends that biomarker candidates for bipolar disorder be investigated from neuroimaging studies, peripheral biomarkers and genetic studies in these three main study titles [4].

Although the etiology of bipolar disorder has not been fully elucidated, neuroimaging studies, genetic and biochemical investigations have provided important insights into the process of bipolar disorder [3]. There are many studies on the neurobiological basis of bipolar disorder 
but its pathophysiology is not fully known. Brain imaging methods are potentially very important for obtaining information about the pathophysiology of bipolar disorder. Structural and functional imaging techniques have clearly contributed to a better understanding of the etiology of bipolar disorder and the development of a diagnostic approach. Recent advances in brain imaging methods have increased the knowledge about abnormalities in neural systems underlying the disease and in various regions of the brain [5]. The purpose of this study, to review the abnormalities that occur in various regions of the brain in bipolar disorder and briefly refer to its reflection in psychiatric nursing care.

Even though there is no more suspicion that bipolar disorder is a brain disorder, the underlying neuroanatomical causes remain uncertain. Significant deterioration developed in neurocognitive and emotional areas in bipolar disorder has been the focus of research in the past decade. Deterioration of balance between pathways in a brain is considered as a result of excessive emotional reactivation, and impaired regulation of emotions in bipolar disorder. This deterioration occurs as a result of functional hyperactivation in the ventral limbic tract and hypoactivation in the cortical-cognitive pathway $[6,7]$.

Studies that examine all brain regions structurally and functionally support a neurobiological model which reports that there is a hyperactive subcortical structure and hypoactive cortical-cognitive structure in bipolar patients. These deficits detected in bipolar patients are thought to be the result of the deterioration of the neural structures which connects the lateral orbitofrontal, dorsolateral prefrontal and anterior cingulate cortex to striatum, and to thalamus via globus pallidus, the substantia nigra [8].

According to the results of Hoenou, et al. [9], there is a reduction in right precentral gyrus, right anterior cingulate, and left inferior frontal gyrus gray matter in bipolar patients. Furthermore, it has been observed in functional studies that there is a reduction especially in the cortical-cognitive pathway in bipolar patients (ventrolateral prefrontal cortex, dorsolateral prefrontal cortex, anterior cingulate cortex, precuneus). In addition, it has also been reported that there is an increase in neural activation in ventral-limbic brain structures (parahippocampal gyrus and amygdala).

The prefrontal cortex, which contains dorsolateral, ventromedial, and orbitofrontal circuits that are thought to form a common anatomical structure in mood disorders, is one of the key regions regulated by mood. The prefrontal cortex is the place where internal, external, conscious and unconscious information from all sources is stored as memory, and information from organ centers is organized and combined to determine behavior. In some of the adult bipolar disorder imaging studies, it has been shown that the prefrontal context is reduced compared to healthy volunteers $[10,11]$. Reduced prefrontal gray matter volumes have been reported by Lopez-Larson, et al. [12], especially in the middle and upper regions, and in the lower and middle regions on the right, in manic or mixed attack.

Cingulate and parahippocampal gyrus together form the limbic cortex. Cingulate is in a dense neuronal relationship with both limbic structures such as amygdala, hippocampus and hypothalamus and prefrontal and postcentral cortical areas as well as the basal ganglia [13].

Hippocampal formation, which is one of the important parts of the memory system, is a part of the forebrain and located in the medial temporal lobe. A large number of afferent fibers related to all senses enter directly or indirectly in hippocampus. The hippocampus is defined as the link region between perception and memory systems. The hippocampus is a part of the fronto-limbic circuit associated with memory and it regulates mood together with parahippocampal cortex and amygdala. Studies show that hippocampus volumes have not changed [10].

Lateral ventricles are one of the most important structures due to some features. These characteristics can be listed as the involvement of lateral ventricles in neural tissues, variation of shape and size, flexible and expandable structure, and passage of autonomic pathways such as motor, sensory and endocrine centers on their walls [14]. Studies have shown that there is significant enlargement was found in left and right lateral ventricles in bipolar disorder. Previous manic episodes and lateral ventricular enlargement were found to be related to each other [15-17].

Thalamus is one of the key structures in neuroanatomical circuits that are thought to play a role in the pathophysiology of mood disorders and in the connection between the cortical and subcortical brain regions. The studies about the enlargement and shrinking of thalamus are contradictory. Thalamus is thought to play a role in the pathophysiology of functional disorders, despite conflicting findings on structural anomalies in thalamus.

Amygdala and hippocampus play a key role in regulating our mood and behaviors. Both are components of the limbic system [18]. The amygdala and the hippocampus process the inputs in the form of emotion expression. It is accepted that the specialized memory function of the amygdala is to recognize objects and to attach emotionally labeled tags to their memory footprints. Le Doux [19] has found that people whose amygdala is removed have an inability to assess the emotional meaning of events and they have in a sense emotional blindness. The difference between the amygdala and the hippocampus, two of the main memory centers of the brain, is that the hippocampus remembers dry facts and amygdala remembers by establishing emotional 


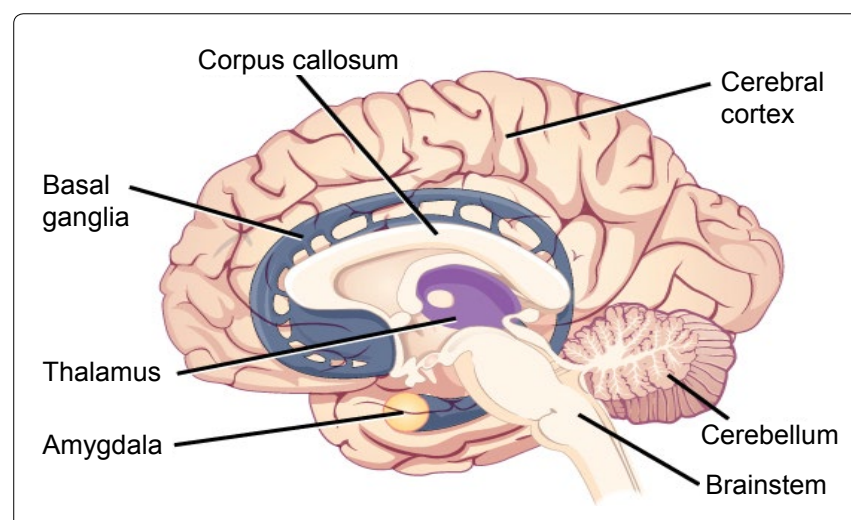

Figure 1: These illustrations show the sagittal sections of the human brain. Available at: [30].

connections. Amygdala is a limbic system part that plays a role in the programming of generally appropriate behavioral responses. The amygdala, which receives efferent nerves from all senses, mainly smell, hearing, sight and somatosensorial senses, is also treated like a limbic system window that shows the situation of the person at that position. It is thought that the formation and perception of emotions such as joy, excitement, anger and sadness are provided by the cingulate gyrus and the orbitofrontal cortex. It is also accepted that the outward appearance of emotions in the form of laughter, crying, and fury is realized by the hypothalamus and amigdala.

It is currently being investigated whether amygdala abnormalities in adolescents with bipolar disorder are the result of developmental issues or these abnormalities are formed due to bipolar disorder. Blumberg, et al. [20] conducted structural Magnetic Resonance Imaging (MRI) studies on amygdala in adult bipolar disorder and they have reported significantly reduced amygdala volumes compared to controls, as opposed to other adult studies. Pearlson, et al. [21] have reported significantly reduced left amygdala volumes in adults with bipolar disorder compared to controls (Figure 1).

Studies have indicated that prefrontal cortex in euthymic patients and healthy family members show deficits in verbal memory, learning and executive function areas associated with the temporolimbic cycle. It is emphasized that neurocognitive deficits are determinants of the course and severity of the disease in patients with bipolar disorder [22]. While recurrent attacks are associated with progressive cognitive decline, severe cognitive decline is considered to be a sign of poor prognosis for the bipolar patient [23].

It is thought that white matter abnormalities in bipolar patients may be an important biomarker. However, the underlying pathophysiology is unknown. In the imaging studies, deficits and reductions in white matter especially hyperintense in deep white matter have been reported in bipolar patients [24]. Vederine, et al. [25] have conducted a study in which they measure white matter abnormalities in patients with bipolar disorder by using the Diffusion Tensor Imaging (DTG) method.
According to their findings, they have reported a right white matter reduction especially near the parahippocampal gyrus. Important anatomical structures in this region are superior longitudinal fascicle, inferior fronto-occipital fascicle, inferior longitudinal fascicle, and posterior thalamic facia. These four paths are the major transmission paths. These pathways play an active role in the skills of defining the emotions in the face, in conscious emotional experiences, and in automatic emotional processing. The functioning of these emotional processes is impaired in bipolar patients. Changes in functional communication in these regions that regulate the process of recognizing and processing emotions are thought to be the cause of the symptoms observed in bipolar patients.

With the development of new imaging techniques, studies investigating the pathophysiology and treatment effects of bipolar disorder are rapidly increasing. However, most of these studies are not the first stage studies but also have some limitations. These limitations can be listed as the low number of samples, the presence of comorbid disorders, the different periods of the disease, and the frequent occurrence of multiple drug treatments [26]. For all that clarification of the neurobiological bases of the disease will also be reflected in the quality of the nursing care to be given to the bipolar patients.

Understanding the structural and functional features and functioning of the brain is the basis of psychiatric nursing practices. Also it is thought that it is obviously necessary to use all knowledge models to assist a bipolar patient as a psychiatric nurse. Psychiatric nurses are thought to change the chemistry of the patient's brain, as well as the intrapsychic state of the patient, through the therapeutic relationship and communication they establish with patients [27]. They support the development of new neural connections with psychotherapy, psychotropic drugs, and psychosocial interventions. They can manage care for symptoms that may develop or have already developed due to structural changes in the brain [28].

Psychiatric nurses are also responsible for the education of patients and their relatives. Bipolar patients and their families usually learn the developments in pathophysiology through the media and the internet. However, this new information seem complicated and uncertain for patients and their families. Psychiatric nurse should follow the new developments related to the disorder and inform the patient and the family about the illness process. Psychiatric nurse should explain the difference between the hypothesis and facts about the illness to the patient and his family. Furthermore, psychiatric nurse should explain how new investigations will affect the treatment and prognosis of the patient [29]. As a result, we think that knowing the structural and functional changes in the brain in bipolar disorder as a psychiatric nurse in all this information will affect the care of the bipolar patient positively. 


\section{Conflict of Interest}

The authors declare no conflict of interest.

\section{References}

1. Varcarolis EM (2013) Bipolar Spectrum Disorders. Essentials of Psychiatric Mental Health Nursing. ( $2^{\text {nd }}$ edn), Elsevier Saunders, China, 277-297.

2. Özerdem A (2013) İkiuçlu bozukluklar. In: Yemez B, Tunca Z, Yetişkin psikiyatri. Rotatıp, İzmir, 141-173.

3. Özalp DCT (2014) Bipolar bozuklukta oksidatif DNA hasarı, onarımı ve oksidatif hasarın nörotrofik faktörler ile ilişkisi. Uzmanlık Tezi, Dokuz Eylül Üniversitesi, İzmir.

4. Frey BN, Andreazza AC, Houenou J, Jamain S, Goldstein $\mathrm{BI}$, et al. (2013) Biomarkers in bipolar disorder: A positional paper from the International Society for Bipolar Disorders Biomarkers Task Force. Aust N Z J Psychiatry 47: 321-332.

5. Kara K, Akarsu S, Verim S (2013) Bipolar bozuklukta nörogörüntüleme. Psikiyatride Güncel Yaklaşımlar 5: 1-14.

6. Blumberg HP, Charney DS, Krystal JH (2002) Frontotemporal neural systems in bipolar disorder. Semin Clin Neuropsychiatry $7: 243-254$.

7. Phillips ML, Ladouceur CD, Drevets WC (2008) A neural model of voluntary and automatic emotion regulation: implications for understanding the pathophysiology and neurodevelopment of bipolar disorder. Mol Psychiatry 13: 829, 833-857.

8. Lloyd AJ, Moore PB, Cousins DA, Thompson JM, McAllister VL, et al. (2009) White matter lesions in euthymic patients with bipolar disorder. Acta Psychiatr Scand 120: 481-491.

9. Houenou J, Frommberger J, Carde S, Glasbrenner M, Diener $C$, et al. (2011) Neuroimaging-based markers of bipolar disorder: evidence from two meta-analyses. J Affect Disord 132: 344-355

10. Monkul ES, Özerdem A (2003) Bipolar Bozuklukta Yapısal Manyetik Rezonans Görüntüleme (MRG) Çalışmaları. Turk Psikiyatri Derg 14: 225-232.

11. Cummings JL (1993) Frontal-subcortical circuits and human behavior. Arch Neurol 50: 873-880.

12. López-Larson MP, DelBello MP, Zimmerman ME, Schwiers ML, Strakowski SM (2002) Regional prefrontal gray and white matter abnormalities in bipolar disorder. Biol Psychiatry 52: 93-100.

13. Doris A, Belton E, Ebmeier KP, Glabus MF, Marshall I (2004) Reduction of cingulate gray matter density in poor outcome bipolar illness. Psychiatry Res 130: 153-159.

14. Avcı E, Karataş D (2014) Lateral Ventrikül Anatomisi. Türk Nöroşir Derg 24: 1-8.

15. Strakowski SM, DelBello MP, Zimmerman ME, Getz GE, Mills NP, et al. (2002) Ventricular and periventricular struc- tural volumes in first- versus multiple-episode bipolar disorder. Am J Psychiatry 159: 1841-1847.

16. Arnone D, Cavanagh J, Gerber D, Lawrie SM, Ebmeier KP, et al. (2009) Magnetic resonance imaging studies in bipolar disorder and schizophrenia: meta-analysis. $\mathrm{Br} \mathrm{J}$ Psychiatry 195: 194-201.

17. Hallahan B, Newell J, Soares JC, Brambilla P, Strakowski SM, et al. (2011) Structural magnetic resonance imaging in bipolar disorder: An international collaborative mega-analysis of individual adult patient data. Biol Psychiatry 69: 326-335.

18. Nagode JC, Pardo JV (2002) Human hippocampal activation during transitive inference. Neuroreport 13: 939-944.

19. Le Doux J (1996) The Emotional Brain. Simon \& Schuster, New York, USA.

20. Blumberg HP, Kaufman J, Martin A, Whiteman R, Zhang $\mathrm{JH}$, et al. (2003) Amygdala and hippocampal volumes in adolescents and adults with bipolar disorder. Arch Gen Psychiatry 60: 1201-1208.

21. Pearlson GD, Barta PE, Powers RE, Menon RR, Richards SS, et al. (1997) Medial and superior temporal gyral volumes and cerebral asymmetry in schizophrenia versus bipolar disorder. Biological Psychiatry 41: 1-14.

22. Zubieta JK, Huguelet P, O'Neil RL, Giordani BJ (2001) Cognitive function in euthymic bipolar I disorder. Psychiatry Res 102: 9-20.

23. Demirel A, Demirel ÖF, Kadak MT, Duran A (2012) Ötimik bipolar hastalarda nörobilişsel defisitler. Psikiyatride Güncel Yaklaşımlar 4: 381-395.

24. Kempton MJ, Geddes JR, Ettinger U, Williams SC, Grasby PM (2008) Meta-analysis, database, and meta-regression of 98 structural imaging studies in bipolar disorder. Arch Gen Psychiatry 65: 1017-1032.

25. Vederine FE, Wessa M, Leboyer M, Houenou J (2011) A meta-analysis of whole-brain diffusion tensor imaging studies in bipolar disorder. Progress in Neuro-Psychopharmacology and Biological Psychiatry 35: 1820-1826.

26. Coşkun M (2009) Bipolar bozukluğu olan çocuk ve ergenlerde psikiyatrik eş tanılar. Uzmanlık Tezi, Tıp Fakültesi, İstanbul Üniversitesi, İstanbul.

27. Hayes A (1995) Psychiatric nursing: What does biology have to do with it? Arch Psychiatr Nurs 9: 216-224.

28. Perese EF (2012) Psychiatric advanced practice nursing: A biopsychsocial foundation for practice. F.A. Davis Company, Philadelphia, USA.

29. Videbeck $S$ (2013) Psychiatric-mental health nursing. $\left(6^{\text {th }}\right.$ edn), Lippincott Williams \& Wilkins, China.

30. http://archive.cnx.org/contents/71795734-f72d-43f9-875b3a8d8fece7c3@2/derived-copy-of-the-central-nervoussystem 